\title{
A Route to Improving Elongation of High-Temperature Laser Sintered PEKK
}

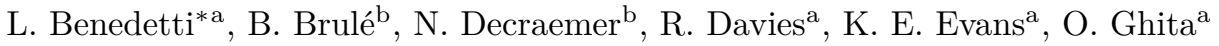 \\ ${ }^{a}$ University of Exeter, College of Engineering, Mathematics and Physical Sciences, EX4 4QF Exeter, United Kingdom \\ ${ }^{b}$ Arkema, Cerdato, Route du Rilsan, 27470 Serquigny, France
}

\begin{abstract}
Laser Sintering (LS) is one of the most popular additive manufacturing (AM) techniques as it produces parts of complex geometry with high dimensional accuracy and good mechanical strength. However, the nature of the LS process often leads to brittle behavior characterized by a low elongation at break if compared to conventional polymer processing techniques, e.g., injection molding (IM). For poly(ether ketone ketone) (PEKK), such elongation is currently below $3 \%$. This study determines and then optimizes the relationship between cooling time and crystallization during LS and the resulting elongation at break. The elongation at break of PEKK was successfully improved by using shorter times of cooling. The combination of the slow crystallization kinetics of PEKK and short cooling time of $1 \mathrm{~h}$ increased elongation at break to 14\%; this is a striking result never achieved for PAEKs in LS before. A calibration curve was developed that can be used to correlate PEKK structure and mechanical properties to cooling conditions according to the application. This methodology can also be applied to select and optimize the mechanical properties of other LS polymers sharing similar kinetics of crystallization and processing temperatures. This work suggests that there is enormous potential for a wide range of "post-processing" heat treatments to be used in AM to tailor the ultimate mechanical properties.
\end{abstract}

Keywords:

Laser Sintering, PEKK, mechanical properties, elongation at break, cooling time

\section{Introduction}

Laser Sintering (LS) is one of the most established and widely used Additive Manufacturing (AM) techniques [1]. This technology uses a laser as a heat source to fuse particles together on the powder bed and manufacture a 3D part, layer-by-layer. Similar to other AM techniques, LS has been proven to help reduce production times and is able to manufacture parts with complex geometries without the need for tooling. LS also enables part manufacture with excellent mechanical properties in small to medium batch

\footnotetext{
* Corresponding author.

Telephone number: +44 (0) 1392725831

E-mail address: lb636@exeter.ac.uk 
volumes, therefore it is often preferred over other AM techniques such as Fused Deposition Modeling (FDM) $[2]$.

From the range of mechanical properties, elongation is drastically affected in parts produced by LS [3]. In the horizontal plane in parallel to the layers, similar tensile strength is achieved to in comparison with injection molded (IM) parts, but elongation at break is significantly reduced. To illustrate the brittle behavior of LS specimens, Duraform polyamide 12 (PA12), a widely used material in LS, shows an elongation at break between 200 - 300\% when processed by IM, but only of $14 \%$ when processed by LS [2]. For EOS PEK HP3, the difference in elongation at break varies from almost 100\% with IM to 3\% with LS [4]. Other poly(aryl ether ketone)s (PAEKs) grades have exhibited similar poor values for elongation [5]. Two factors may be causing poor elongation in LS: process properties, and intrinsic material behavior. Examples of process properties include layer interfaces, particle-to-particle interfaces [6], porosity, and partial coalescence $[7,8]$. These sources of failure are not homogeneous across the build but highly dependent on the orientation of manufacturing $[4,7]$. For intrinsic material properties, crystallization has the dominant effect over elongation.

Some studies have found an increase in elongation at break for polymers with higher molecular weight $\left(M_{w}\right)[9,10]$. Zarringhalam et al. [11] compared the elongation at break of two different PA12, EOS PA2200, and Duraform PA12, under three different conditions: virgin, refreshed (67\% used powder and $33 \%$ virgin powder), and used (100\% used powder). They found an increase in $M_{w}$ from $70,000 \mathrm{~g} \mathrm{~mol}{ }^{-1}$ for virgin to $170,000 \mathrm{~g} \mathrm{~mol}^{-1}$ for used PA2200 powder. The elongation at break followed a similar trend, and the specimens built with refreshed and used powder showed higher values of elongation, which was attributed to the $M_{w}$ increase. When investigating the microstructure, the spherulites of both PA12 grades processed by LS are significantly larger than IM and showed unmolten particle cores from which crystals are formed. The unmolten cores matched the DSC analysis in which the particle cores presented a higher melting peak. The melted structure presented a lower melting temperature $\left(T_{m}\right)$ than the virgin powder but is still within the temperature of $\gamma$ form. The authors attributed the difference to the thermal processing conditions.

Garcia-Leiner et al. [12] found key differences in the crystallization rate and degree of crystallinity amongst other properties of injection molded PEEK with different molecular weight and molecular weight distribution. The degree of crystallinity was approximately $8 \%$ higher for the grades with lower molecular weight, while their crystallite size increased by $1 \mathrm{~nm}$. Interestingly, the grades with lower $M_{w}$ showed higher mechanical strength $(\sim 98.9 \mathrm{MPa})$ and elongation at break $(>55 \%)$ than the grades with higher $M_{w}$ processed by IM. These results contradict Zarringhalam et al. [11] findings, in which elongation of PA12 was greater for a higher $M_{w}$. Garcia-Leiner et al. [12], however, attributed their values to the increase in the degree of crystallinity of injection molding (IM) specimens with lower $M_{w}$.

Ajoku et al. [13] found a compression strain of $15 \%$ for LS PA12 against $17 \%$ when PA12 is processed by IM and tested under compression. The reduction in ductility of LS specimens was associated with process 
properties - part porosity and incomplete melting - and material properties, such as the increase in the level of crystallinity, the spherulites growth obtained with the slow cooling in LS, but mainly the little or no entanglement between the spherulite crystals. In this study, the tensile modulus and yield strength of LS specimens were higher than IM; they attributed that to the increase in crystallinity of LS specimens as a result of the prolonged cooling time.

The slow cooling in LS should allow sufficient time for full particle coalescence and bonding as well as chain rearrangement for crystal formation and growth [9]. An increase in the cooling time, however, may change the crystal structure and the degree of crystallinity. Zhu et al. [14] found an increase in the degree of crystallinity, the presence of $\gamma$ phase and a coarser microstructure for PP manufactured by LS. In contrast, the rapid cooling rate of injection molded PP led to a lower degree of crystallinity, the absence of $\gamma$ phase and a finer microstructure. These differences resulted in higher tensile strength and tensile moduli for the specimens produced by LS, but lower elongation at break if compared to IM.

Wang et al. [15] observed a significant increase in the level of crystallinity of poly(ether ether ketone) (PEEK) powder subjected to LS. The LS specimens revealed a hierarchical spherulitic crystal composed of three structures. In the primary structure, the size of crystal blocks varies from 20 to $30 \mathrm{~nm}$. A secondary structure bonds the crystal structure together in a less ordered arrangement. Then, a third structure of granular crystal blocks is observed, which is formed by the combination of primary crystal blocks and secondary structure with size varying between 75 and $145 \mathrm{~nm}$.

PEKK, and similarly PEEK belong to the PAEKs family of polymers. This family of polymers has an orthorhombic crystal structure, which crystallizes in the form of spherulites. The degree of crystallinity can vary from $0 \%$ to $42 \%[15,16]$. PEKK is also a polymorph and can crystallize in two different forms: form I and form II. In the primary structure (form I), phenyl-phenyl interactions are aligned edge-to-face. In the secondary structure (form II), phenyl-phenyl interactions are aligned face-to-face [17]. Some studies [18, 19] claim that form II can only be obtained under solvent crystallization or cold crystallization. Garcia-Leiner et al. [20] found that both forms can be present under certain conditions in LS and Fused Deposition Modelling (FDM) of PEKK. However, no details were provided.

This research aims to find a clear relationship between cooling time, polymer crystallinity, and elongation at break. PEKK crystallinity is sensitive to process temperature and cooling time; by controlling such process parameters, it is possible to improve the elongation of PEKK manufactured by LS, which is currently below $3 \%$ [5]. This calibration curve can, therefore, be used to control polymer structure and mechanical properties for a range of applications with different needs. 


\section{Materials and Experimental Work}

\subsection{Materials}

The experiments were conducted with Kepstan 6002 PEKK powder supplied by Arkema [21]. This grade is commercially available under the name of PEKK HPS1 and is synthesized using diphenyl ether at a concentration ratio of 60/40 of terephthalic acid (T) with para phenyl links and isophthalic acid (I) with meta phenyl links $[21,22]$. Kepstan 6000 PEKK has a glass transition temperature $\left(\mathrm{T}_{\mathrm{g}}\right)$ of $160{ }^{\circ} \mathrm{C}$ and a melting temperature $\left(\mathrm{T}_{\mathrm{m}}\right)$ of $300{ }^{\circ} \mathrm{C}$.

The Kepstan 6000 PEKK powder has been studied extensively in previous research [5, 23]. The particle size distribution of PEKK has a $\mathrm{D}(10)$ of $33.34 \mu \mathrm{m}$, a $\mathrm{D}(50)$ of $52.8 \mu \mathrm{m}$, and a $\mathrm{D}(90)$ of $87.87 \mu \mathrm{m}$ [5]. The powder flow properties were analyzed using a Freeman Technologies FT4 powder rheometry. The basic flowability energy and stability index are of $155 \pm 9 \mathrm{~mJ}$ and $1.48 \pm 0.2$ respectively, where the bulk density of Kepstan 6000 PEKK is $0.36 \mathrm{~g} \mathrm{ml}^{-1}$ [23].

\subsection{Tensile testing}

Tensile testing was performed using a Shimadzu AGX-plus equipment with a maximum force of 2 tonnes. The test followed ISO 527-2-1BA guidelines, in which the testing speed corresponds to $1 \mathrm{~mm} \mathrm{~min}^{-1}$. The specimens have an approximate length of $80 \mathrm{~mm}$, a testing width of $5 \mathrm{~mm}$, and $4 \mathrm{~mm}$ of thickness. The calculation of elastic modulus considered a deformation of $0.2 \%$ in the elastic region. The elongation was monitored using TRViewX non-contact digital video extensometer coupled to the universal testing equipment. The sample size included at least ten specimens for each group.

\subsection{Wide X-ray diffraction}

Wide X-ray diffraction (WXRD) was used to measure the degree of crystallinity of the specimens manufactured in each group of the build, and to briefly investigate crystal phase. This experiment used a Bruker D8 advanced X-ray diffractometer with $\mathrm{Cu} \mathrm{K \alpha}(\gamma=0.1542 \mathrm{~nm})$ radiation and a LynxEye detector operating at a voltage of $40 \mathrm{kV}$ and a current of $40 \mathrm{~mA}$. The data was collected in a fixed time mode (1 s) with a step size of $0.05^{\circ}$ and run from $2 \theta=4$ to $65^{\circ}$. The degree of crystallinity was measured on the top surface of two specimens of each group, one manufactured in the corner and the other in the middle of the LS powder bed, using DIFFRAC V6.0 software. The calculation of the crystallinity was performed by carefully selecting the background baseline first, and then dividing the sum of the peak areas by the total area (crystalline + amorphous phase) of the spectrum.

\subsection{Statistical analysis}

ANOVA statistical analysis was used to investigate the statistical significance of the mechanical testing results and the degree of crystallinity of LS PEKK specimens. IBM SPSS Statistics 26 [24] software was 
employed to perform one-way ANOVA using a confidence level of $95 \%$ and the Tukey option for the post-hoc test. The level of significance was explored regarding 'P-values', with values below 0.05 being statistically significant.

\subsection{Scanning Electron Microscopy}

Scanning electron microscopy (SEM) was selected to investigate surface fracture of LS specimens of Kepstan 6000 PEKK. The analysis used a TESCAN VEGA3 scanning electron microscope at an accelerating voltage of $10 \mathrm{kV}$ and a current of $0.13 \mathrm{nA}$. The specimens were coated with $10 \mathrm{~nm}$ thick of chromium to reduce surface charging. The captured images had magnifications varying from $30 \times$ to $15,000 \times$.

\section{Choice of Temperature for Build Setup}

\subsection{Cooling in high-temperature laser sintering}

The high-temperature LS (HT-LS) process comprises three main cooling stages, as shown in Figure 1. The first stage [a] is in the order of milliseconds and starts from the laser application until the scanned layer reaches the temperature provided by the infrared heaters, known as the bed temperature $\left(T_{b e d}\right)$ [28]. The second cooling stage [b] takes place during manufacturing, while new parts are built, and the specimens already sintered and located at the bottom of the build are gradually cooled down. This stage has a more controlled cooling rate determined by $T_{b e d}$ and the building platform temperature $\left(T_{b p}\right)$, usually 15 to 30 ${ }^{\circ} \mathrm{C}$ below $T_{b e d}$. The $T_{b p}$ is the temperature provided by the ceramic heaters and is measured on the piston. These temperatures are illustrated in the EOS P 800 configuration of Figure 2. Lastly, following parts completion, the build goes through the standard cooling phase (Figure 1[c]) set by the system's software according to the volume and distribution of the built parts and the total height of the build in the z-direction. This rate of the cooling stage is unknown, but the heating completely switches off below the glass transition temperature, $T_{g}$, as illustrated in Figure 1.

The first cooling phase is crucial as warping, and part distortion can take place if the powder bed is too cold [29]. If shrinkage is controlled [28], however, cooling during the process determines the final part quality, as it significantly affects consolidation and mechanical performance. The slow cooling in LS should allow sufficient time for full particle coalescence and bonding as well as chain rearrangement for crystal formation and growth [9]. To avoid crystallization at the first stage of cooling and promote full adhesion between layers, materials for LS can be chemically modified to delay solidification by slowing down the kinetics of crystallization [30]. This is the case of Kepstan 6000 Poly(ether ketone ketone) (PEKK) [21] commercialized by Arkema.

When manufactured by IM or extrusion calendaring, Kepstan 6000 PEKK is completely amorphous due to the rapid rate of cooling of these processes and the slow kinetics of crystallization of PEKK, as supported 


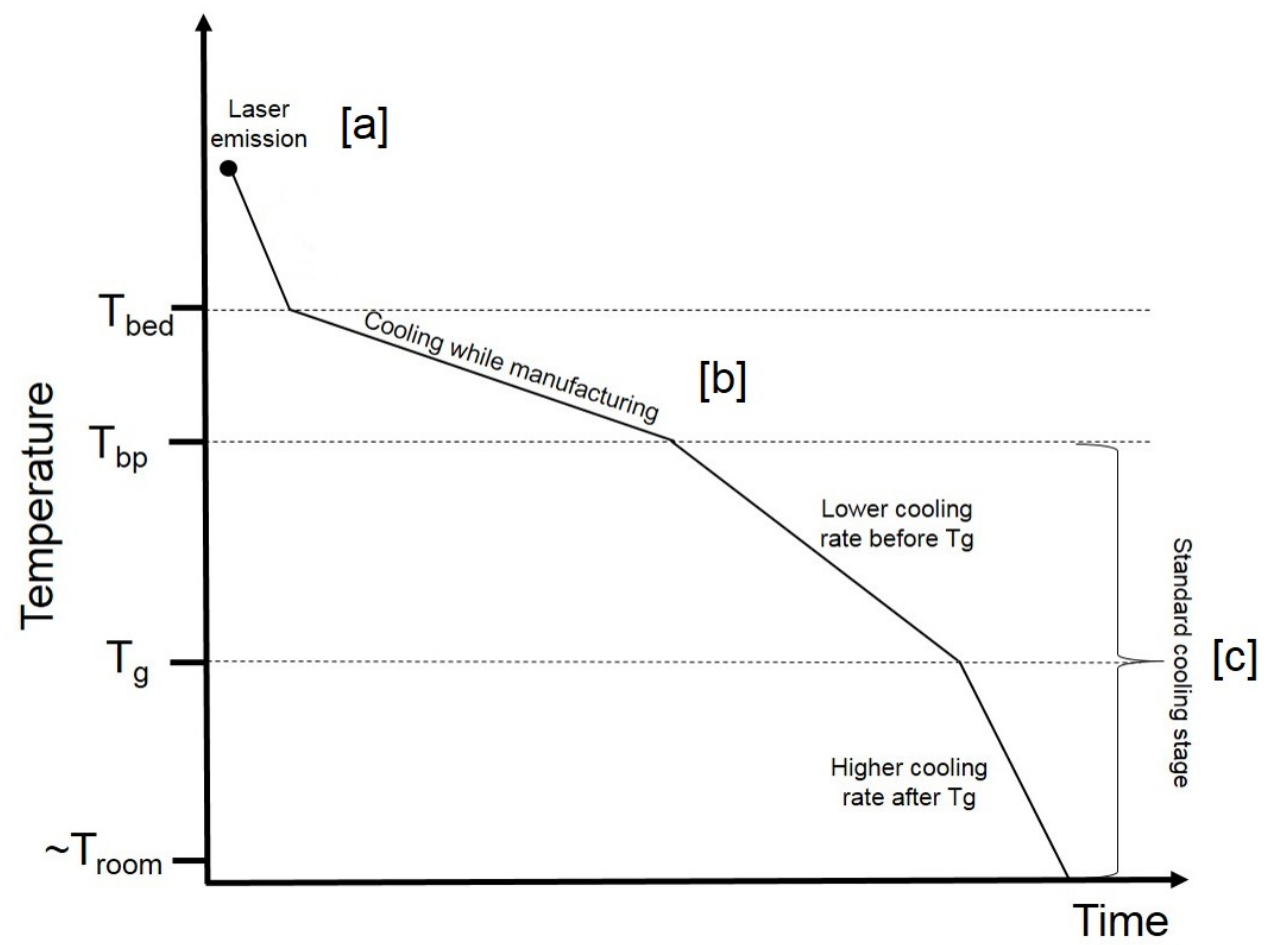

Figure 1: Schematic representation of the cooling profile in an HT-LS system. Following the completion of part production $[a-b]$, the system goes through the standard machine cooling [c], which comprises two cooling stages with different rates.

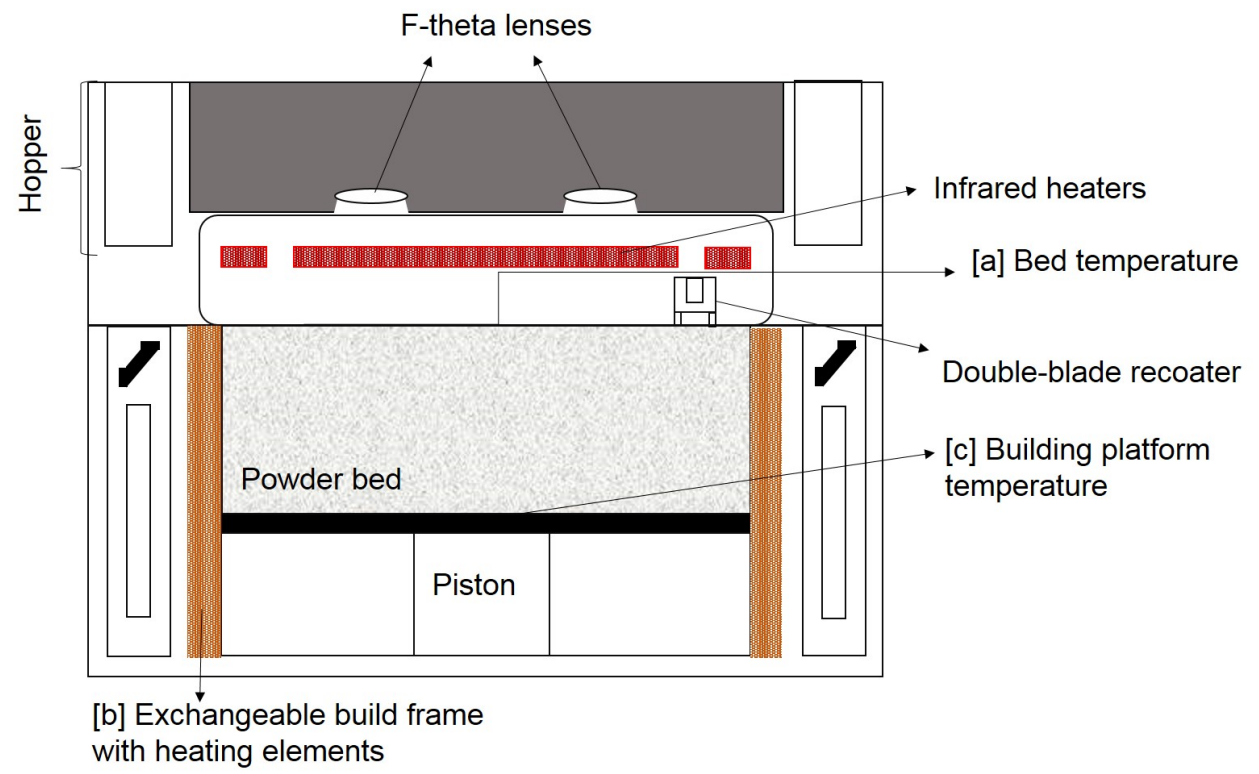

Figure 2: Schematic illustration of the EOS P 800 HT-LS system showing main components and temperatures. (a) Bed temperature, (b) exchangeable build frame temperature, and (c) building platform temperature. 

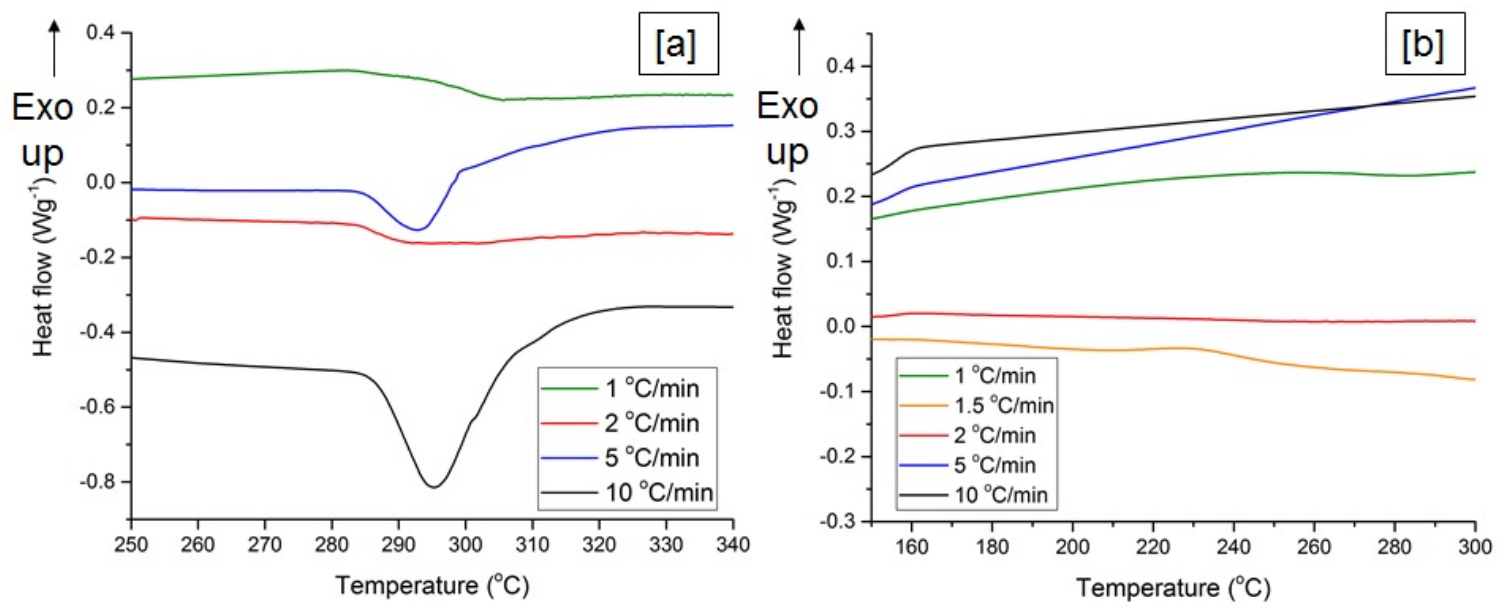

Figure 3: DSC profiles for Kepstan 6000 PEKK at different [a] heating and [b] cooling rates. The melting peak becomes broader at lower heating rates [a], and no crystallization peak is observed at cooling [b].

by the DSC measurements in dynamic condition (Figure 3) [22]. However, during LS, sufficient time is provided for the organization of the molecules into a crystalline lattice. The relationship between material and process is, therefore, crucial to obtain the desired properties of PEKK processed by LS.

\subsection{Crystallization kinetics}

The kinetics of the crystallization of Kepstan 6000 PEKK powder was firstly investigated using a differential scanning calorimeter (DSC). The experiments were executed using a Mettler Toledo 821e/700 DSC, and the Stare SW 12.10 software [25] was used for data analysis. The tests were performed dynamically and isothermally with a nitrogen flow rate of $50 \mathrm{ml} \mathrm{min}{ }^{-1}$.

For the dynamic tests, powder samples with a weight varying between $5 \mathrm{mg}$ to $10 \mathrm{mg}$ were placed in aluminum pans with a volume of $40 \mu \mathrm{L}$. The sample was heated from room temperature to $400{ }^{\circ} \mathrm{C}$ at $10{ }^{\circ} \mathrm{C}$ $\mathrm{min}^{-1}$ rate and then cooled to room temperature using the same rate. Different heating and cooling rates were applied, varying from $1{ }^{\circ} \mathrm{C} \mathrm{min}^{-1}$ to $10{ }^{\circ} \mathrm{C} \mathrm{min}^{-1}$. Figure 3 shows the heating [a] and cooling [b] curves obtained for Kepstan 6000 PEKK powder. As opposed to Kepstan 6000 PEKK in pellet format, which is amorphous, PEKK in powder format presents a melting point (Figure 3[a]), supporting its semi-crystalline behavior. The cooling rate (Figure $3[\mathrm{~b}]$ ), however, affects the crystallization kinetics of PEKK chains, which at $10{ }^{\circ} \mathrm{C} \mathrm{min}-1$ are not able to organize into a crystalline structure. Cooling rates below $2{ }^{\circ} \mathrm{C} \mathrm{min}^{-1}$ resulted in a shallow crystalline peak of difficult measurement. Therefore, isothermal measurements were conducted.

The isothermal tests were performed using $100 \mu \mathrm{L}$ aluminum pans to allow more material in the analysis. Powder samples were heated at $20^{\circ} \mathrm{C} \mathrm{min}-1$ from $25^{\circ} \mathrm{C}$ to $380{ }^{\circ} \mathrm{C}$, then quickly cooled at $80{ }^{\circ} \mathrm{C} \mathrm{min}{ }^{-1}$ to the chosen isotherm temperature. The isotherm was maintained for 120 min followed by cooling up to $25{ }^{\circ} \mathrm{C}$, at $20{ }^{\circ} \mathrm{C} \mathrm{min}-1$. This prolonged isotherm was chosen due to the slow crystallization of PEKK. The isotherm 
temperatures varied from $200{ }^{\circ} \mathrm{C}$ to $270{ }^{\circ} \mathrm{C}$ at an interval of $10{ }^{\circ} \mathrm{C}$.

The isotherms were investigated in terms of half-time crystallization, which refers to the time taken to crystallize to half of the maximum relative crystallinity of PEKK at each isotherm. This procedure is usually performed with the assistance of a flash-DSC piece of equipment due to the fast organization of the polymeric chains. Paolucci et al. [26] and Tardif et al. [27] successfully applied this procedure to PA 2200 and PEEK 150G, respectively. For PA2200, the minimum point of the curve is of $0.1 \mathrm{~s}$ at $85{ }^{\circ} \mathrm{C}$ [26]. For PEEK 150G, Tardif et al. [27] obtained values of $0.3 \mathrm{~s}$ for the temperature of maximum rate of crystallization $\left(\sim 230^{\circ} \mathrm{C}\right)$. In the case of Kepstan 6000 PEKK, the crystallization is one order of magnitude slower, which classifies this material as a slow-crystallizing polymer. The half-time crystallization curve of Kepstan 6000 PEKK is shown in Figure 4. The resulting U-shape curve has a minimum time near $230{ }^{\circ} \mathrm{C}$, which corresponds to the temperature in which PEKK crystallizes the fastest $(\sim 7 \mathrm{~min})$. This curve agrees with the results obtained by Choupin et al. [22]. The half-time crystallization curve of Figure 4 will be used as a basis to select the processing temperatures in LS and to understand the relationship between process and kinetics of crystallization of Kepstan 6000 PEKK.

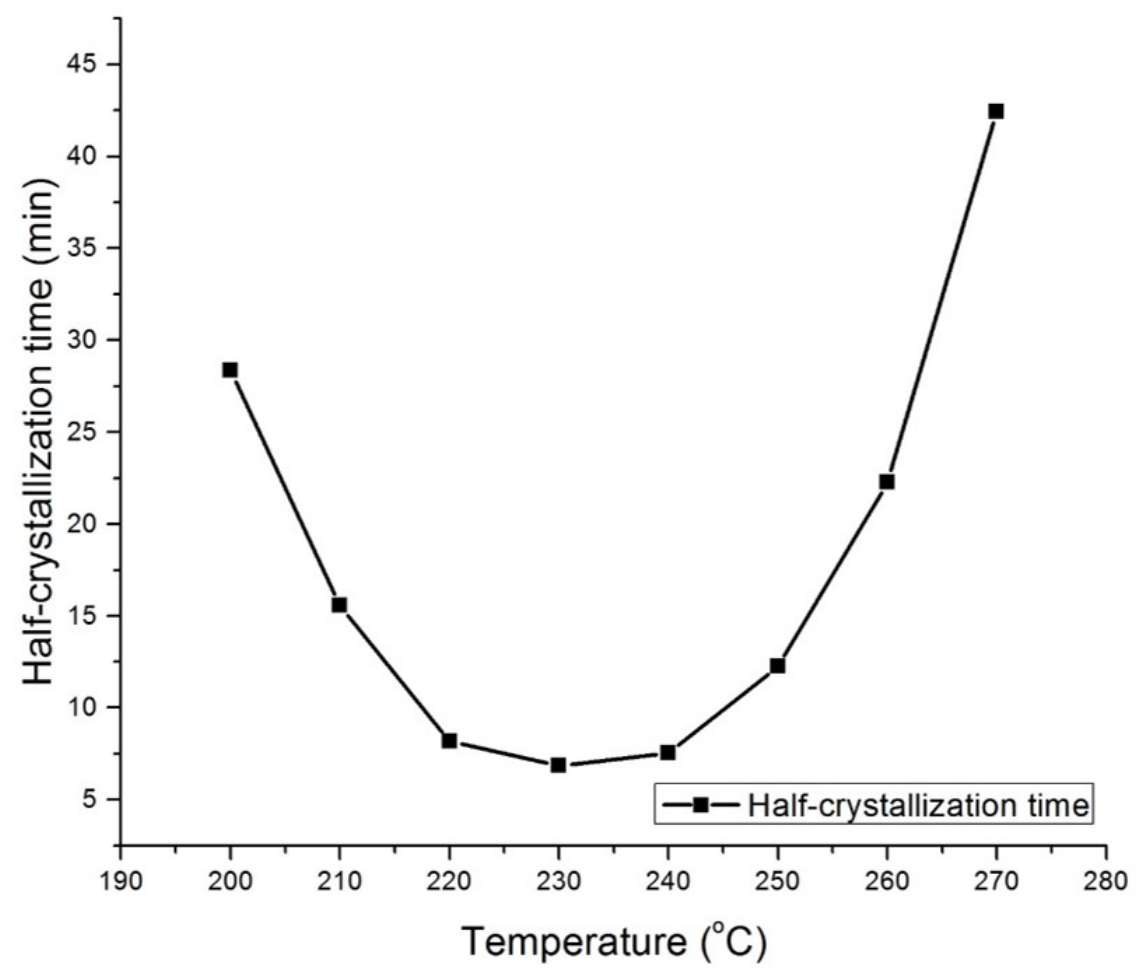

Figure 4: Time taken to crystallize to half of the maximum crystallization of Kepstan 6000 PEKK under different isothermal temperatures, also known as the half-time crystallization curve.

Finally, the enthalpy induced by the crystallization cycle was measured; the results are shown in Figure 5. The enthalpy of fusion follows similar trend to Figure 4 , and is minimum in the edges $\left(\sim 9 \mathrm{~J} \mathrm{~g}^{-1}\right)$, but 
achieves a maximum at $240{ }^{\circ} \mathrm{C}$, of $17.8 \mathrm{~J} \mathrm{~g}^{-1}$.

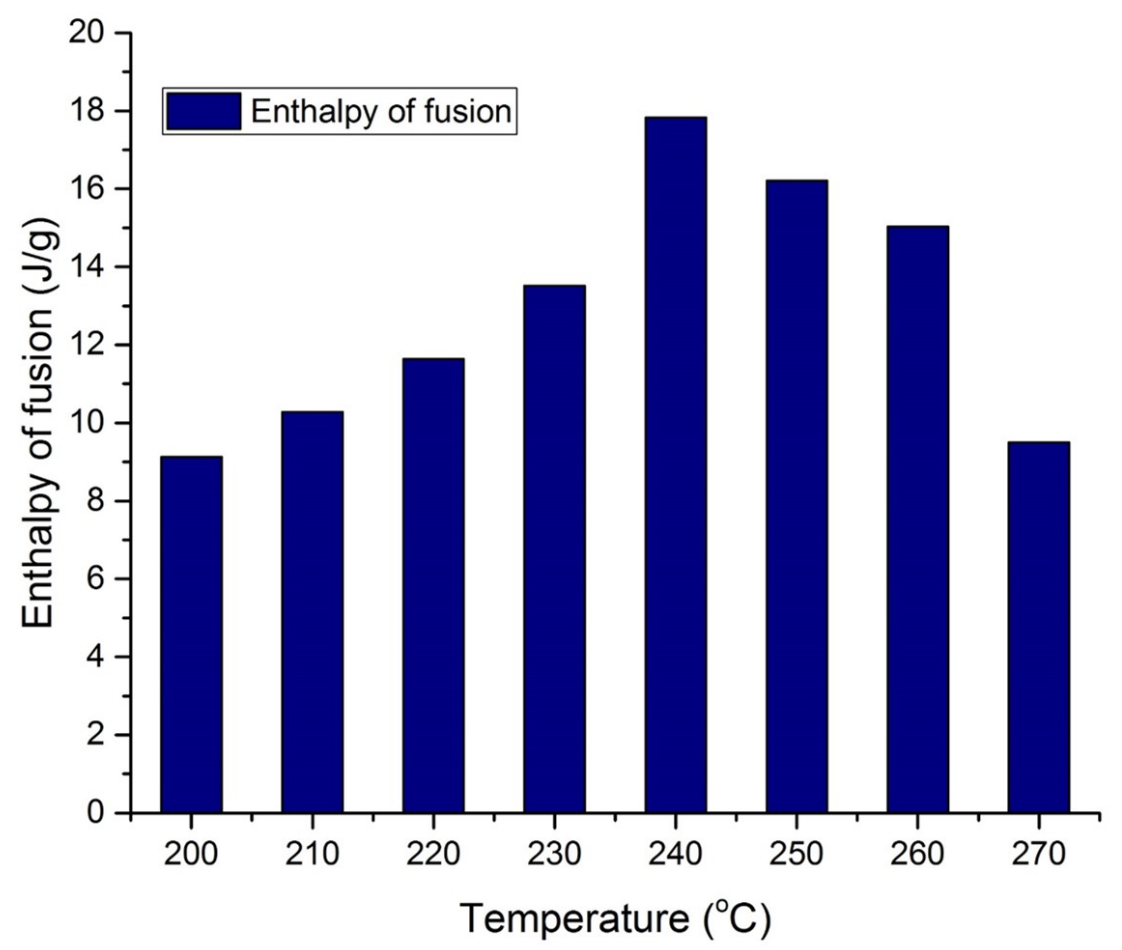

Figure 5: Enthalpy of fusion of Kepstan 6000 PEKK taken from DSC experiments at different isotherms. Note the maximum enthalpy of fusion at $240{ }^{\circ} \mathrm{C}$.

\section{Build Setup and Manufacture}

This experimental setup was designed to investigate the crystallization of Kepstan 6000 PEKK during LS and the effect of cooling time in the final mechanical properties. A High-Temperature (HT) EOS P 800 LS system was used in the reduced chamber configuration (one-third of the maximum volume), as shown by Berretta et al. [31]. The best mechanical performance of LS Kepstan 6000 PEKK is achieved with a total energy density of $23.5 \mathrm{~mJ} \mathrm{~mm} \mathrm{~mm}^{-2}$ applied to each layer of $120 \mu \mathrm{m}$ [5]. Using the first derivative method described by Berretta et al. [32], the minimum point of the first derivative of the heating curve of PEKK is equal to $292{ }^{\circ} \mathrm{C}$, which seems to be the ideal temperature to guarantee full coalescence, minimum warp, and best mechanical properties [5].

As shown in Section 3.2, the crystallization spectrum of PEKK has its extremes at $200{ }^{\circ} \mathrm{C}$ and 270 ${ }^{\circ} \mathrm{C}$, which signifies that at temperatures below $200{ }^{\circ} \mathrm{C}$ or above $270{ }^{\circ} \mathrm{C}$, crystallization is minimum or even inexistent. At $270{ }^{\circ} \mathrm{C}$, the ability of chain realignment is facilitated by the reduced viscosity of the liquid phase and the increase of free energy within the system. These factors are strong enough to disrupt any 
potential nuclei before growth takes place, therefore increasing the time for polymer nucleation and the formation of spherulitic crystallites. As the temperature lowers, the rate of crystallization significantly increases up to a limit $\left(230-240{ }^{\circ} \mathrm{C}\right)$, and then gradually decreases again [33], as shown in Figure 4. At temperatures near $200{ }^{\circ} \mathrm{C}$, chain mobility is significantly reduced while the viscosity of the liquid phase increases. The combination of these phenomena decreases the possibility of nuclei formation [34].

Considering the crystalline behavior of PEKK and aiming to investigate the entire spectrum of crystallization during manufacture, the $T_{b p}$ selected was of $190{ }^{\circ} \mathrm{C}$. It is important to note that the temperature distribution across the powder bed of LS systems, especially the EOS P 800, is not uniform, and temperature fluctuations of $\pm 5{ }^{\circ} \mathrm{C}$ are observed [2].

The build setup consisted of 16 groups of specimens stacked on top of each other in Z orientation. In each group, 10 ISO 527-2-1BA specimens were produced in X orientation. These specimens experienced the same cooling time, therefore combined into groups. The specimens had a 4mm thickness; therefore, $\sim 33$ layers. Half of the specimens were produced in the corner of the build; the other half of the specimens were manufactured in the middle of the build. The groups followed a sequential order from the bottom (group 1) to the top (group 16). The experiment setup took approximately $10.75 \mathrm{~h}$ to complete, excluding the pre-heating stage. Figure 6 shows the complete build configuration as loaded to be manufactured.

Once the last layer of the sixteenth group of specimens was produced, the process was interrupted as quickly as possible, so no powder was added to the top layer. Each group was exposed to different cooling times, as shown in Figure 7. The build was removed from the system and quenched in water at approximately $15{ }^{\circ} \mathrm{C}$. The cake was broken into small parts to help with homogeneous cooling and allow water to penetrate the cake and interrupt further crystallization.

The specimens were left cooling for approximately 12 hours and then removed from the water, cleaned and sandblasted to remove any non-sintered powder. Figure 8 shows the manufactured specimens after cooling and post-processing. The rapid cooling in water led to a small number of samples warping in the groups subjected to less than $4 \mathrm{~h}$ of cooling. In these groups, a total of 13 specimens were warped, which corresponds to $\sim 4 \%$ of the total number of specimens produced (320 specimens). These specimens were removed from the mechanical testing analysis. The significant changes in color are a result of different degrees of crystallinity. While the first groups have a light beige color, the specimens from group 5 assume a darker beige color, which turns to grey from group 8-9. Interestingly, the specimen from group 16 is translucent on the top, but opaque in the bottom. This change in opacity suggests that the upper layers are entirely amorphous, but crystallization begins quickly after. Figure 6 illustrates the color difference of the specimens varying with their location in the build. The experiment was repeated twice. 


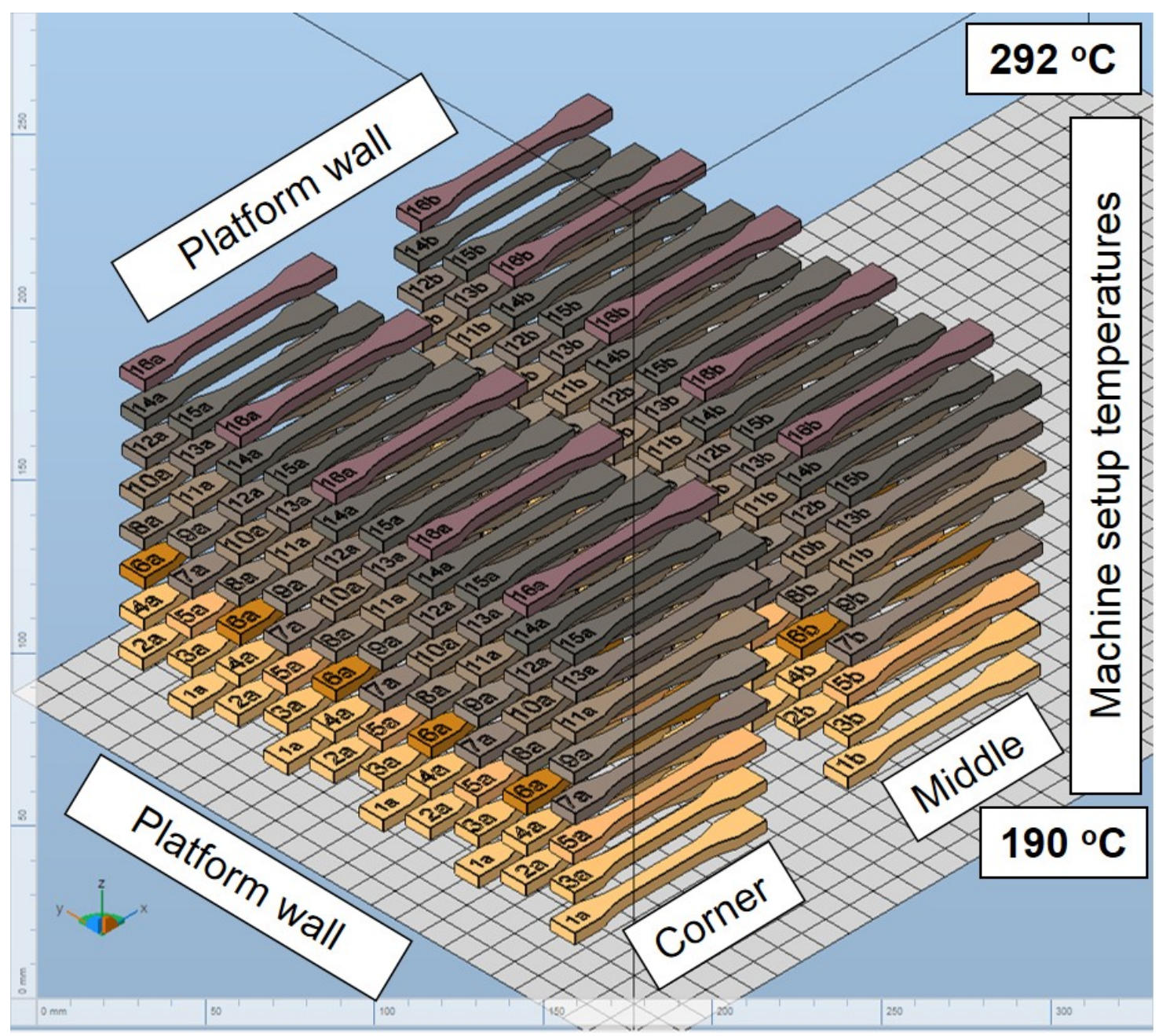

Figure 6: Crystallization build setup. The temperatures of manufacturing, $T_{b e d}$ and $T_{b p}$, are indicated on the right. Group one was the first to be built, following a sequential order until group 16. Therefore, the first group was exposed to the longest time of cooling, as opposed to group 16. The color of the specimens attempted to match the real colors of them when removed from cooling. 


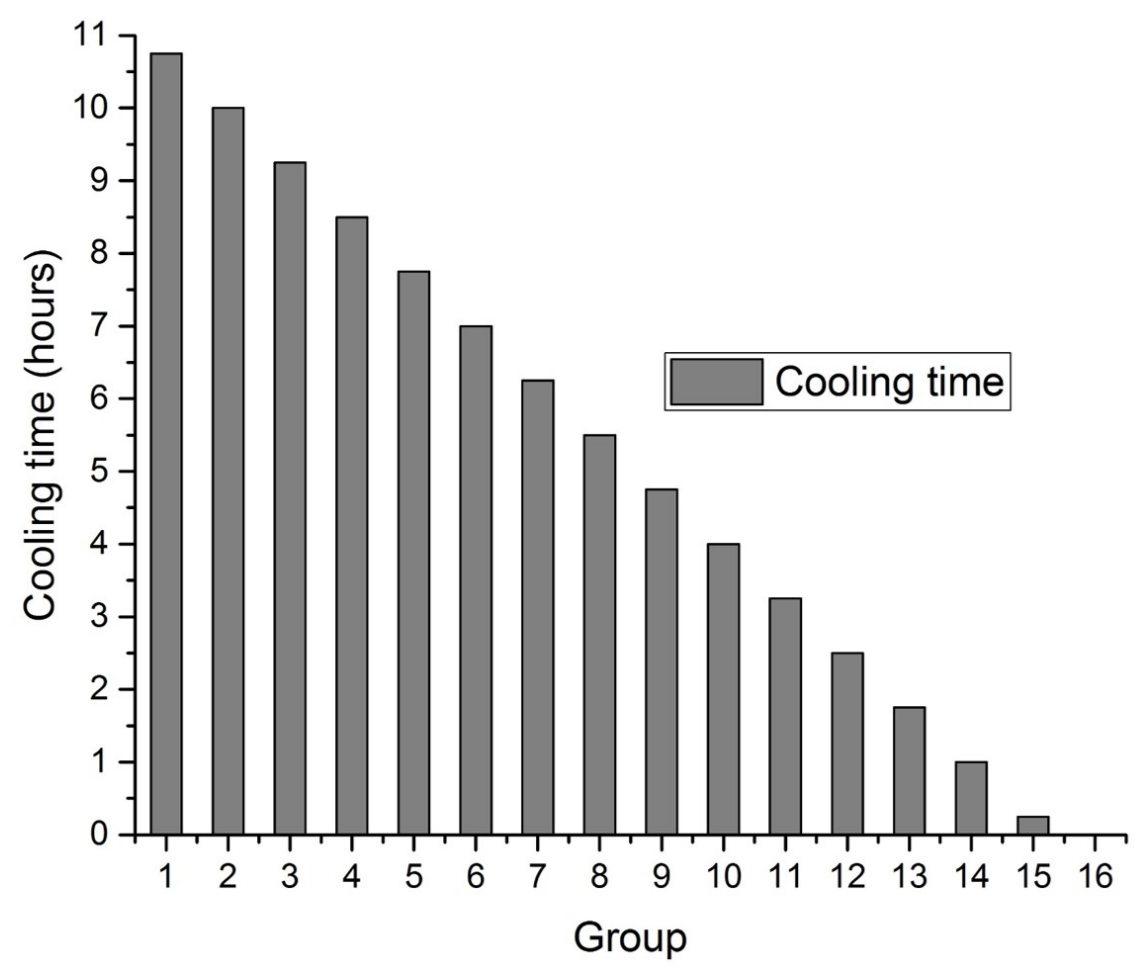

Figure 7: Relationship between cooling time and each group of specimens from the experimental setup.

\section{Results and Discussions}

\subsection{Mechanical performance}

Tensile strength and elongation at break were assessed in terms of cooling time; the results are shown in Figure 9. The majority of the build shows an inverse correlation between mechanical strength and elongation at break, as expected. At more extended cooling periods, sufficient time is given to arrange PEKK crystals fully and therefore increase the degree of crystallinity, as shown by the first three groups in the bottom. These groups have a brittle behavior with an elongation at break below $2.5 \%$, characteristic of LS PAEKs $[35,36]$. At slightly shorter cooling times, the elongation at break more than doubles (5.6\% at $7 \mathrm{~h}$ of cooling) while mechanical strength ranges around $80 \mathrm{MPa}$. The maximum strength $(\sim 82 \mathrm{MPa})$ is obtained at 6.25 $\mathrm{h}$ of cooling, while the elongation at break reaches $13.2 \%$ at one hour of cooling, values never achieved in literature for LS PAEKs.

One-way ANOVA was performed to confirm statistical differences in the data. The parameter chosen for the analysis was elongation at break since this is the factor of primary importance in this study. Table 1 compares the specimens produced at a specific cooling time with the other specimens of the build in terms of significant and non-significant differences, considering $P$ values with $95 \%$ confidence. 
Table 1: One-way ANOVA analysis of the elongation at break of specimens subjected to different cooling times. The specimens manufactured at a specific cooling time (left column) were compared with the other specimens of the build considering a $95 \%$ confidence level.

\begin{tabular}{|c|c|}
\hline Cooling time & $\begin{array}{l}\text { Statistically different }(\mathrm{P}<0.05) \text { from groups } \\
\text { subjected to cooling times of: }\end{array}$ \\
\hline $0 \mathrm{~h}$ & $1 \mathrm{~h} ; \geq 7.75 \mathrm{~h}$ \\
\hline $0.25 \mathrm{~h}$ & $1 \mathrm{~h} ; \geq 7.75 \mathrm{~h}$ \\
\hline $1 \mathrm{~h}$ & $0 \mathrm{~h} ; 0.25 \mathrm{~h} ; 1 \mathrm{~h} ; \geq 4 \mathrm{~h}$ \\
\hline $1.75 \mathrm{~h}$ & $\geq 6.25 \mathrm{~h}$ \\
\hline $2.5 \mathrm{~h}$ & $1 \mathrm{~h} ; \geq 7.75 \mathrm{~h}$ \\
\hline $3.25 \mathrm{~h}$ & $\geq 7 \mathrm{~h}$ \\
\hline $4 \mathrm{~h}$ & $1 \mathrm{~h} ; \geq 7.75 \mathrm{~h}$ \\
\hline $4.75 \mathrm{~h}$ & $1 \mathrm{~h} ; \geq 7.75 \mathrm{~h}$ \\
\hline $5.5 \mathrm{~h}$ & $1 \mathrm{~h}$ \\
\hline $6.25 \mathrm{~h}$ & $1 \mathrm{~h} ; 1.75 \mathrm{~h}$ \\
\hline $7 \mathrm{~h}$ & $1 \mathrm{~h} ; 1.75 \mathrm{~h} ; 3.25 \mathrm{~h}$ \\
\hline $7.75 \mathrm{~h}$ & $\leq 4.75 \mathrm{~h}$ \\
\hline $8.5 \mathrm{~h}$ & $\leq 4.75 \mathrm{~h}$ \\
\hline $9.25 \mathrm{~h}$ & $\leq 4.75 \mathrm{~h}$ \\
\hline $10 \mathrm{~h}$ & $\leq 4.75 \mathrm{~h}$ \\
\hline $10.75 \mathrm{~h}$ & $\leq 4.75 \mathrm{~h}$ \\
\hline
\end{tabular}



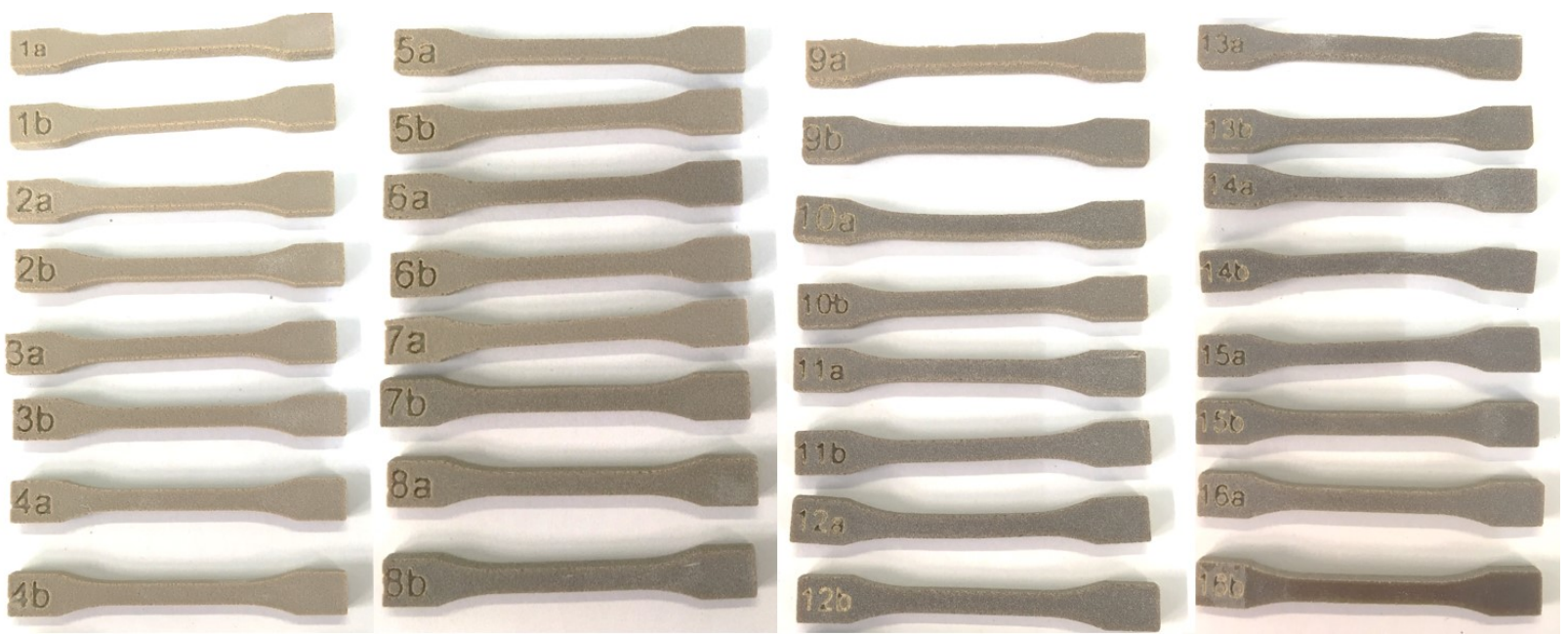

Figure 8: Specimens removed from the cake, cleaned, and sandblasted. Note the change in color with cooling time. The specimens of lighter color remained cooling in the system for a longer time; therefore, they are more crystalline. In contrast, the darker specimens are less crystalline due to the shorter time for cooling.

The values suggest that elongation at break only becomes statistically different in groups separated by an interval of at least $4 \mathrm{~h}$ from each other, with few exceptions mostly at low cooling times ( $\sim 1 \mathrm{~h}$ and below). The trend, however, highlights the potential differences between groups, which may be statistically insignificant because of the heterogeneous quench in water. The group of specimens subjected to $1 \mathrm{~h}$ of cooling, however, was mostly different from the other groups; this may be due to the striking elongation of $13.2 \%$ in comparison with the other specimens. The groups exposed to $4.75 \mathrm{~h}$ and $7.75 \mathrm{~h}$ presented remarkable differences possibly associated with changes in material structure, such as the degree of crystallinity and the start of secondary crystallization.

Figure $9[\mathrm{~b}]$ shows the insignificant changes in the mechanical behavior of specimens subjected to the same cooling time but manufactured at different locations in the powder bed, corner, or middle. The variations in the final performance of PEKK specimens is minimum regardless of higher heat dissipation in the corners of the build. The large standard deviations, especially for specimens in the bottom and on the top of the build, can be explained by the build interruption and sudden cooling in cold water.

The specimens were also assessed in terms of elastic modulus against elongation at break. These results are shown in Figure 10. The elastic modulus has the highest average at the fourth group ( $8.5 \mathrm{~h}$ of cooling) and corresponds to $4.3 \mathrm{GPa}$. Despite following the same trend as tensile strength, the variations are lower, and the elastic modulus achieves a minimum of $\sim 3 \mathrm{GPa}$ (group 13).

\subsection{Crystallization}

WXRD analysis was used to measure the degree of crystallinity of two specimens from each group, one manufactured in the corner and the other in the middle. The results are summarized in Figure 11. 

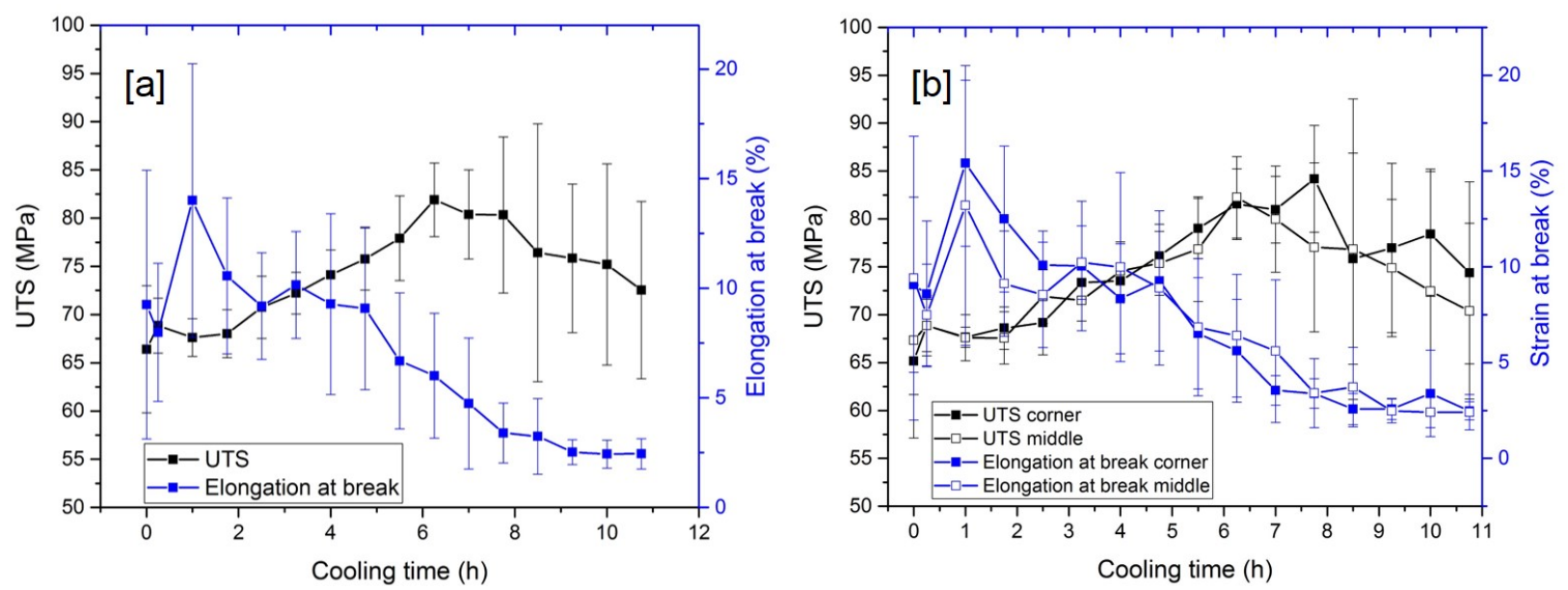

Figure 9: Mechanical performance of specimens produced at different cooling times; [a] average tensile strength and elongation at break varying with cooling time and $[\mathrm{b}]$ average mechanical performance separated by location in the powder bed, corner and middle.

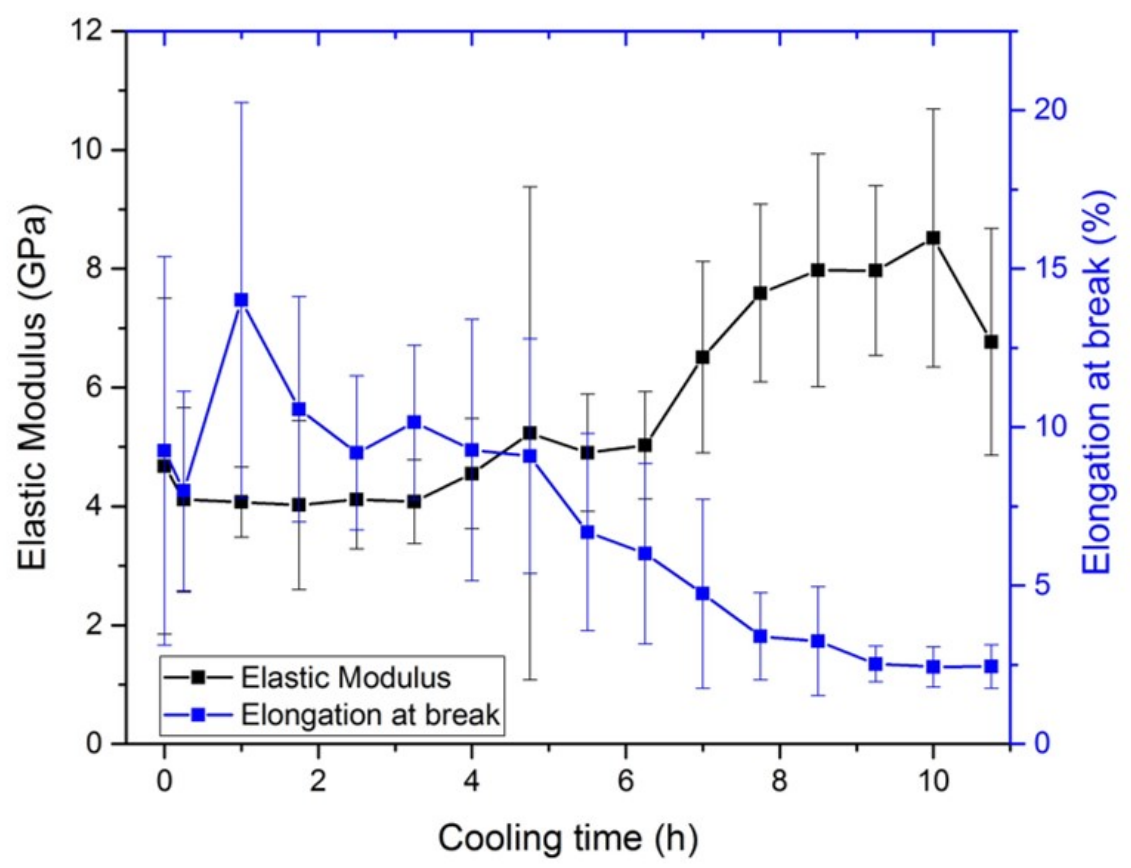

Figure 10: Average elastic modulus vs. elongation at break for specimens produced at different cooling times. 


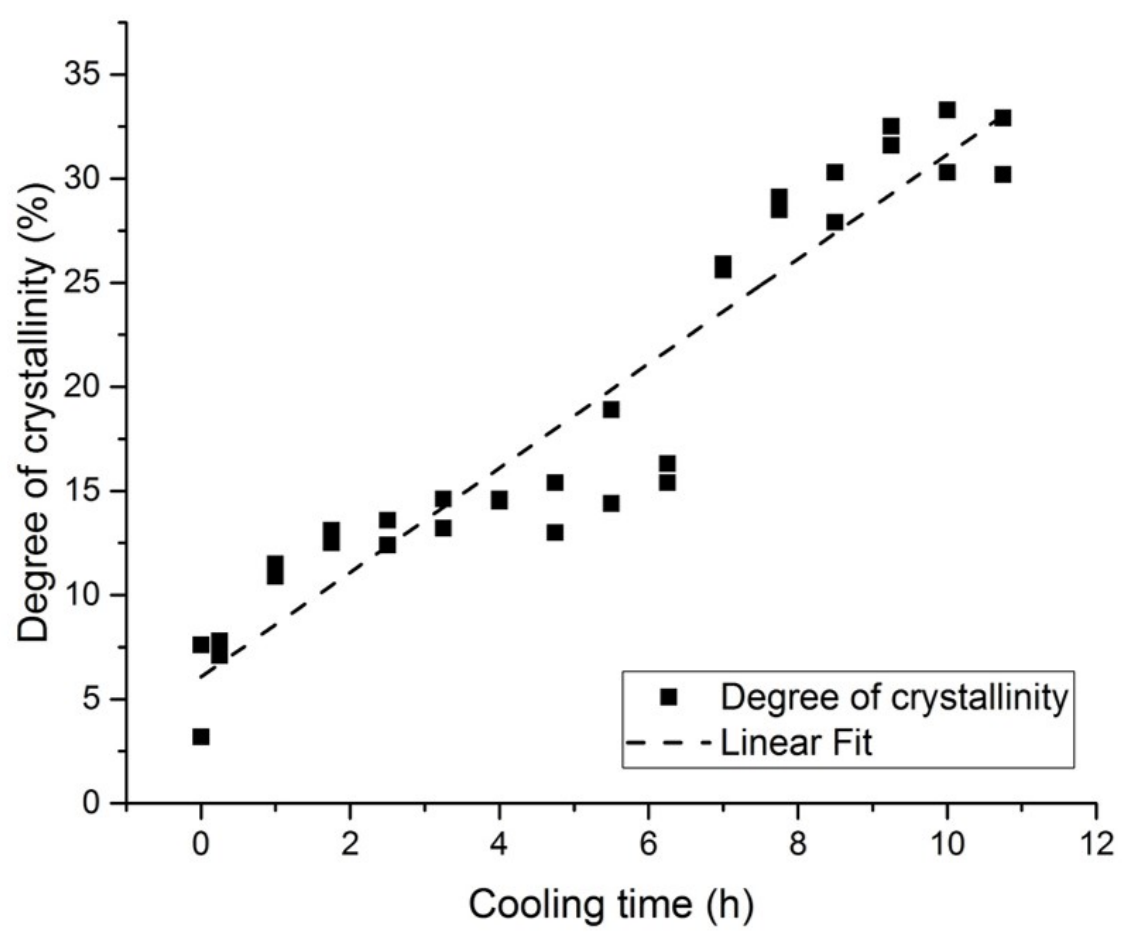

Figure 11: Degree of crystallinity for the specimens manufactured at different cooling times.

The curve shows a correlation of 0.9 between cooling time and degree of crystallinity. When measured on the top surface of the specimens, group 16 showed a completely amorphous behavior, as expected by the extremely reduced cooling times combined with the slow crystallization kinetics of PEKK. One-way ANOVA was conducted by comparing the degree of crystallinity of the specimens groups subjected to different cooling times. The results are shown in Table 2. As opposed to the elongation at break results, the differences between each group is more significant for the level of crystallinity. This result is possibly associated by the exclusion of manufacturing defects, i.e., warping, crack, and porosity affecting intrinsic material properties. For most of the groups, a difference of three hours in cooling time is sufficient to result in statistically significant data, and several groups are already different with cooling times lower than two hours.

A clear step in the level of crystallinity is observed from $6.25 \mathrm{~h}$ to $7 \mathrm{~h}$, from $\sim 16 \%$ to almost $26 \%$. This step can also be represented by two asymptotic curves, one from 0 to $6.25 \mathrm{~h}\left(R^{2}\right.$ of 0.88$)$, and another from 7 to $10.75 \mathrm{~h}\left(R^{2}\right.$ of 0.97$)$. The significant change in the degree of crystallinity between $6.25 \mathrm{~h}$ and $7 \mathrm{~h}$ is possibly associated with secondary crystallization occurring in the already formed crystal structures [37]; this may also be responsible for the decrease in the UTS of the specimens subjected to longer cooling times than $6.25 \mathrm{~h}$. A crystallinity value of $32 \%$ is found for the specimens manufactured in the third group. The first two groups were possibly affected by the low building platform temperature of $190{ }^{\circ} \mathrm{C}$, which may have 
Table 2: One-way ANOVA analysis of the degree of crystallinity of specimens subjected to different cooling times. The specimens manufactured at a specific cooling time (left column) were compared with the other specimens of the build in terms of cooling time.

\begin{tabular}{|c|c|}
\hline Cooling time & $\begin{array}{l}\text { Statistically different }(\mathrm{P}<0.05) \text { from groups } \\
\text { subjected to cooling times of: }\end{array}$ \\
\hline $0 \mathrm{~h}$ & $\geq 1.75 \mathrm{~h}$ \\
\hline $0.25 \mathrm{~h}$ & $\geq 3.25 \mathrm{~h}$ \\
\hline $1 \mathrm{~h}$ & $\geq 7 \mathrm{~h}$ \\
\hline $1.75 \mathrm{~h}$ & $0 \mathrm{~h} ; \geq 7 \mathrm{~h}$ \\
\hline $2.5 \mathrm{~h}$ & $0 \mathrm{~h} ; \geq 7 \mathrm{~h}$ \\
\hline $3.25 \mathrm{~h}$ & $\leq 0.25 \mathrm{~h} ; \geq 7 \mathrm{~h}$ \\
\hline $4 \mathrm{~h}$ & $\leq 0.25 \mathrm{~h} ; \geq 7 \mathrm{~h}$ \\
\hline $4.75 \mathrm{~h}$ & $\leq 0.25 \mathrm{~h} ; \geq 7 \mathrm{~h}$ \\
\hline $5.5 \mathrm{~h}$ & $\leq 0.25 \mathrm{~h} ; \geq 7 \mathrm{~h}$ \\
\hline $6.25 \mathrm{~h}$ & $\leq 0.25 \mathrm{~h} ; \geq 7 \mathrm{~h}$ \\
\hline $7 \mathrm{~h}$ & $\leq 6.25 \mathrm{~h}$ \\
\hline $7.75 \mathrm{~h}$ & $\leq 6.25 \mathrm{~h}$ \\
\hline $8.5 \mathrm{~h}$ & $\leq 6.25 \mathrm{~h}$ \\
\hline $9.25 \mathrm{~h}$ & $\leq 7 \mathrm{~h}$ \\
\hline $10 \mathrm{~h}$ & $\leq 6.25 \mathrm{~h}$ \\
\hline $10.75 \mathrm{~h}$ & $\leq 6.25 \mathrm{~h}$ \\
\hline
\end{tabular}



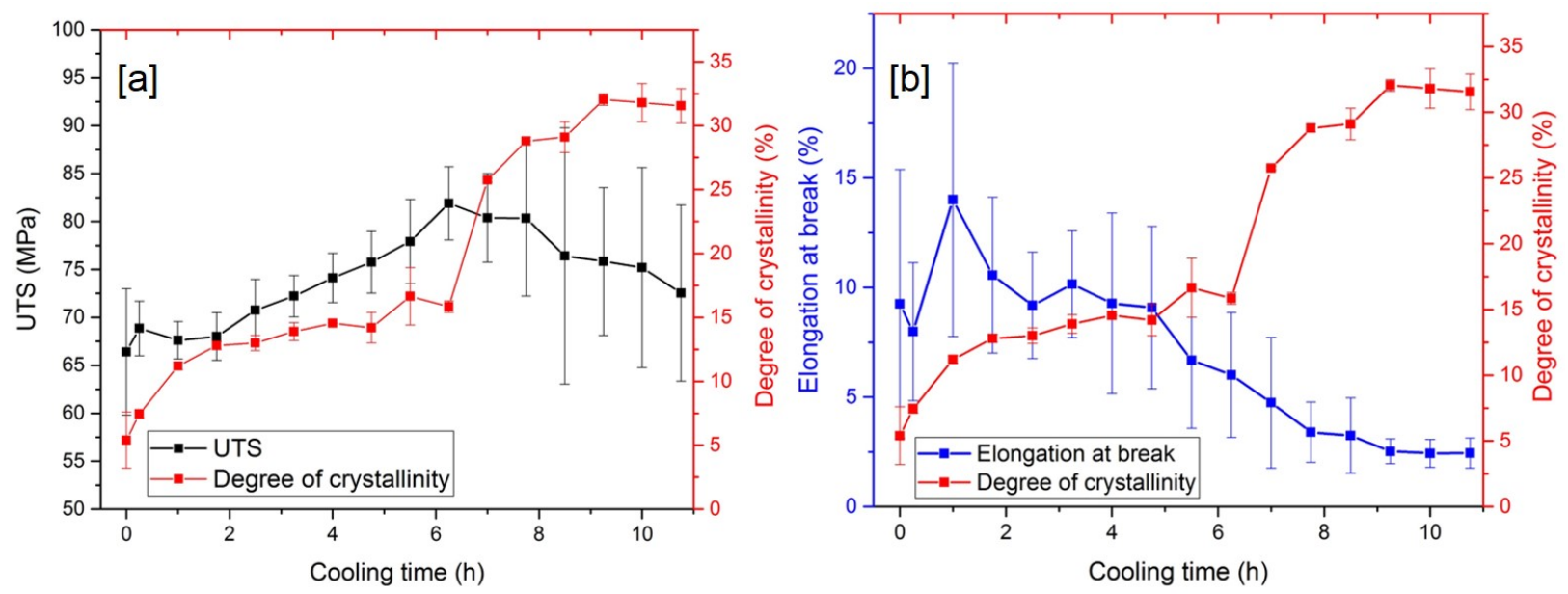

Figure 12: Average degree of crystallinity vs. [a] tensile strength and [b] elongation at break for specimens produced at different cooling times.

increased the cooling rate. This increase is supported by the mechanical test results shown in Section 5.1. Figure 12 compares the degree of crystallinity with tensile strength (Figure 12[a]) and elongation at break (Figure 12[b]).

The increase in mechanical strength leads to an optimum degree of crystallinity of $\sim 16 \%$ at $6.25 \mathrm{~h}$ cooling time. While the crystallinity rapidly increases from $6.25 \mathrm{~h}$ to $7 \mathrm{~h}$ of cooling (group 6 ), the mechanical strength starts reducing. The elongation at break (Figure $12[\mathrm{~b}]$ ) is maximum at very low crystallinity values, close to fully amorphous conditions (5.4\% of crystallinity). For groups 6 and 7 ( $\sim 26 \%$ and $\sim 16 \%$ of crystallinity), elongation at break varies between 4.7 and $6 \%$. Between 1 and 7 hours the degree of crystallinity varies by $15 \%$. These results show that it is possible to control the crystallization of Kepstan 6000 PEKK in LS and, therefore, significantly change the strength and, mainly, the reduced elongation associated with this process.

Previous studies mentioned that the crystalline structure of PEKK, known as form II, can only be obtained under cold crystallisation or when PEKK is exposed to solvents [12, 38]. Garcia-Leiner et al. [20], however, claimed that form II could be present when processing PEKK by LS or FDM. Figure 13 compares different WXRD patterns of LS samples manufactured in the range of cooling time under analysis.

The longer the cooling time (e.g., $10.75 \mathrm{~h}$ ), the more pronounced are the WXRD peaks of the PEKK patterns, until very shallow peaks are found at $0 \mathrm{~h}$ of cooling. Before achieving an almost $100 \%$ amorphous structure, however, PEKK shows an additional shallow peak at $\sim 15.6^{\circ}$, after $0.25 \mathrm{~h}$ of cooling. This peak is attributed to the presence of form II in the structure; such a peak is not observed in the other patters of Figure 13. Therefore, it is possible to have PEKK organised into form II under certain conditions in LS, i.e., low cooling time. 


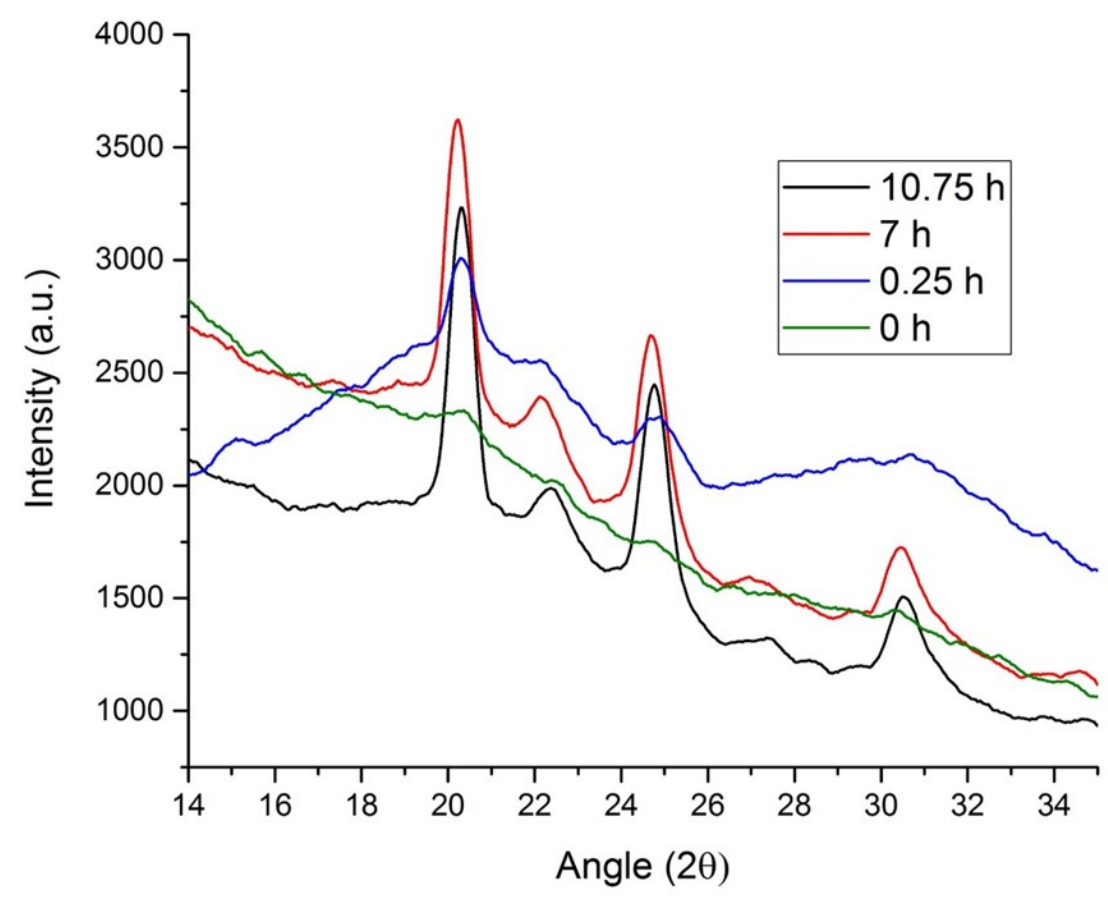

Figure 13: WXRD spectra of LS Kepstan 6000 PEKK specimens subjected to different cooling times.

\subsection{Fracture analysis}

The fracture of the specimens manufactured with different cooling times was investigated; they are shown in Figure 14. Figure 14[1] and [2] present a brittle failure characteristic from low elongation. The failure of the specimen subjected to $9.25 \mathrm{~h}$ of cooling has possibly started on the top right corner as a result of surface imperfections. When magnified, certain regions show some ductile zones trying to hold the structure together. The specimen subjected to $6.25 \mathrm{~h}$ of cooling also showed a brittle failure despite the higher elongation of $6 \%$. This failure seemed to have started from the bottom left corner, where a pore of almost $0.5 \mathrm{~mm}$ is located near the surface. This specimen presents some pores, but more importantly, fibrils which are holding the structure together for longer, therefore enabling a more ductile behavior confirmed by the higher elongation at break.

As opposed to the brittle failure observed in Figure 14[1-2], Figure 14[3] presents a ductile failure with layer delamination. Approximately half of the surface area of the failure shows a very plastic behavior in which a large concentration of pores and delamination are observed. The pores are mostly located in the interlayer area, as pointed by previous studies [3], and mostly in the ductile region. This specimen showed a significant increase in elongation at break, from $6 \%$ at $6.25 \mathrm{~h}$ to $9.1 \%$ at $4.75 \mathrm{~h}$ of cooling. At this cooling time, the degree of crystallinity is $14.2 \%$. The crack may have initiated between the brittle and ductile area.

The ductile behavior is intensified in the specimens of Figure 14[4-5], which behave in an entirely ductile 

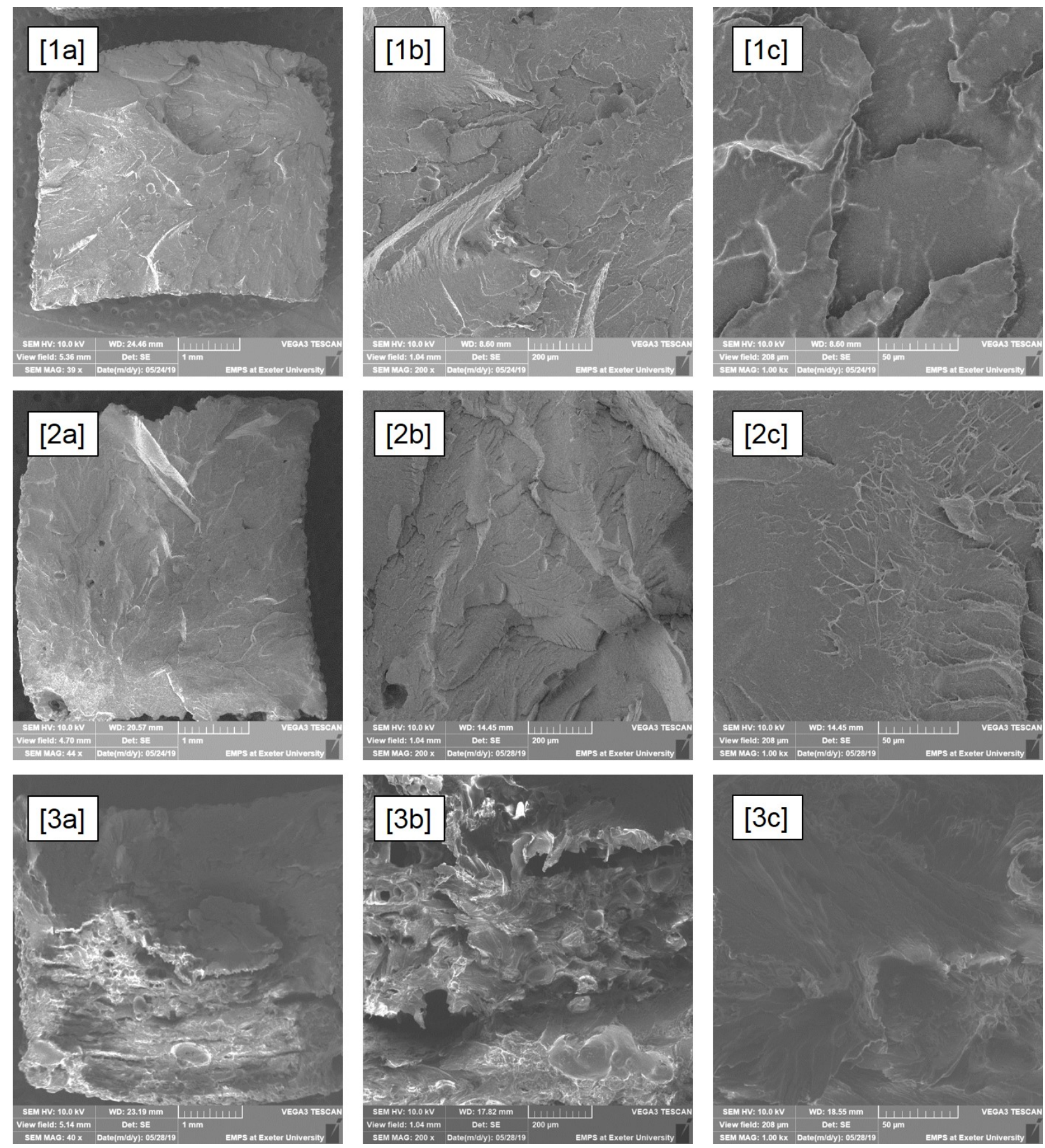

Figure 14: SEM images of the fractured surface of specimens manufactured at [1] $9.25 \mathrm{~h},[2] 6.25 \mathrm{~h},[3] 4.75 \mathrm{~h},[4] 1 \mathrm{~h}$ and [5] 0 $\mathrm{h}$ of cooling time. Note the scale bars of [a] $1 \mathrm{~mm}$, [b] $200 \mu \mathrm{m}$, and [c] $50 \mu \mathrm{m}$. 

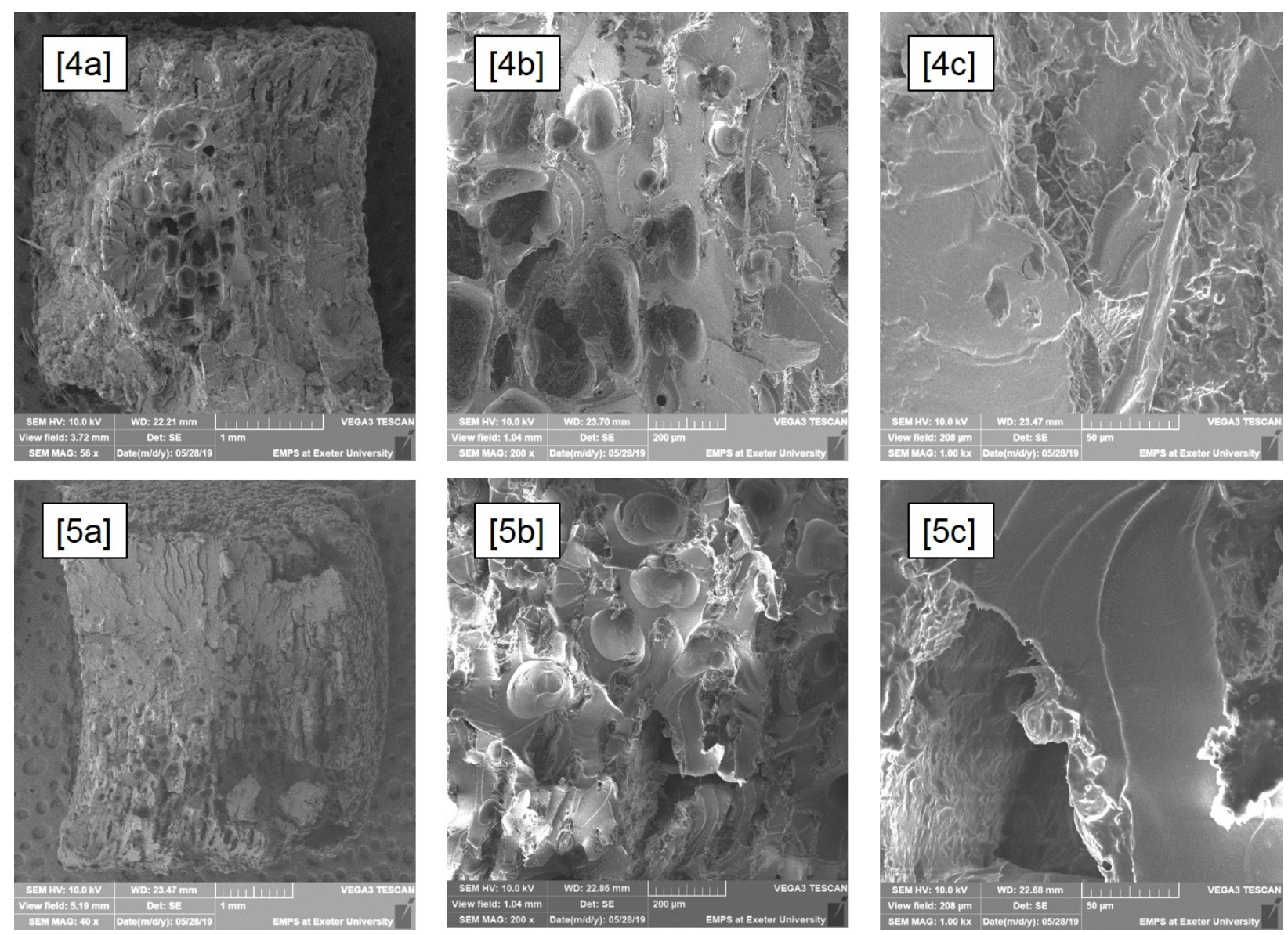

Figure 14: SEM images of the fractured surface of specimens manufactured at [1] $9.25 \mathrm{~h},[2] 6.25 \mathrm{~h},[3] 4.75 \mathrm{~h}$, [4] $1 \mathrm{~h}$, and [5] $0 \mathrm{~h}$ of cooling time. Note the scale bars of [a] $1 \mathrm{~mm}$, [b] $200 \mu \mathrm{m}$ and [c] $50 \mu \mathrm{m}$ (cont.).

fashion. The specimens subjected to $1 \mathrm{~h}$ of cooling have the greatest elongation at break of $13.2 \%$. For the specimen of Figure 14[4], the failure seems to have started from the middle, in which porosity is concentrated, possibly in the interlayer area. Layer delamination may be contributing to failure as well. The specimen with $0 \mathrm{~h}$ of cooling and almost completely amorphous structure (Figure 14[5]) are very ductile, although a brittle failure pattern can be observed in the top area near the surface. This area is free from pores, differently from the more ductile region, in which porosity and layer delamination are observed. Figure $14[5 \mathrm{~b}]$ shows a clear image of the ductile area, trying to hold the structure together before failure.

The SEM failure images confirm the mechanical performance behavior obtained for Kesptan 6000 PEKK under different cooling times. The absence of visible pores in the brittle failure of specimens with longer cooling times is possibly a result of the low elongation. In a ductile failure, however, necking is usually followed by void nucleation, growth, coalescence to form a crack, and finally, fracture [39]. These stages are observed in ductile [40] and glassy polymers [41] due to their plastic behavior that leads to a significantly 
higher deformation. The delamination phenomenon confirms the poor adhesion between layers in LS while deformation is taking place, as supported by Figure 14.

\section{Conclusions}

This study has successfully developed a new procedure to correlate part properties (crystallinity and mechanical performance) with the process (cooling time) of Kepstan 6000 PEKK manufactured by LS. The degree of crystallinity shows a direct relation to mechanical properties, e.g., tensile strength and elongation at break. The poor elongation at break usually found in PAEKs processed by LS [35] is overcome by controlling the cooling time and interrupting crystallization.

Although there is a significant increase in the elongation at break (9\%), the tensile strength decreased by only $17 \%$ at a cooling time of $5 \mathrm{~h}$. When the specimens are subjected to one hour of cooling, strain increases to almost $14 \%$. This increase is a striking achievement as elongation at break was never reported above $5 \%$ for current LS PAEKs [35]. The tensile strength is maintained at $80 \mathrm{MPa}$ with an elongation at break of almost $5 \%$ and a cooling time of $7 \mathrm{~h}$. The edges of the curve, however, show high standard deviations and can be explained by the sudden and heterogeneous quenching of the specimens in water.

The calibration curve is a useful method for predicting final mechanical properties from specific processing conditions. It also introduces another novel feature to AM processing - the "tailoring" of mechanical properties in a vast range of possibilities.

The understanding of how the LS process affects material properties is crucial for successful improvement of final part performance. This study provides an example of the effect of the degree of crystallinity in the mechanical properties of Kepstan 6000 PEKK and shows that it is possible, up to an extent, to control the slow cooling stage of LS to favor the desired properties according to the application. A compromise might be possible, e.g., smaller builds (shorter cooling times) or maybe changes to new LS systems to allow the control of crystallization (different types of cooling). With the drive for faster additive manufacturing to meet the demands for serial production, new systems are being created with modular architecture using two build chambers, exchange modules with robot, and integrated post-processing [42, 43]. There is the possibility that rapid cooling (liquid or gas form) could be added to optimize material properties, and therefore apply a similar solution to improve the mechanical properties of polymers with slow kinetics of crystallization.

\section{Data Availability}

The dataset generated during the current study is not publicly available due to confidentiality reasons but can be made available on reasonable request with the approval of all authors. 


\section{Acknowledgements}

The authors would like to acknowledge the financial support of Arkema Innovations Chemistry for this study.

\section{References}

[1] N. Guo, M. C. Leu, Additive manufacturing: Technology, applications and research needs (2013). doi:10.1007/ s11465-013-0248-8

[2] D. L. Bourell, T. J. Watt, D. K. Leigh, B. Fulcher, Performance Limitations in Polymer Laser Sintering, Physics Procedia 56 (2014) 147-156. doi:10.1016/j.phpro.2014.08.157. URL http://linkinghub.elsevier.com/retrieve/pii/S1875389214003022

[3] A. Wegner, G. Witt, Adjustment of isotropic part properties in laser sintering based on adapted double laser exposure strategies, Optics and Laser Technology 109 (June 2018) (2019) 381-388. doi:10.1016/j.optlastec.2018.08.017. URL https://doi.org/10.1016/j.optlastec.2018.08.017

[4] O. Ghita, E. James, R. Davies, S. Berretta, B. Singh, S. Flint, K. E. Evans, High Temperature Laser Sintering (HTLS): An investigation into mechanical properties and shrinkage characteristics of Poly (Ether Ketone) (PEK) structures, Materials and Design 61 (2014) 124-132. doi:10.1016/j.matdes.2014.04.035.

[5] L. Benedetti, B. Brulé, N. Decraemer, R. Davies, K. Evans, Mechanical Performance of Laser Sintered Poly (Ether Ketone Ketone), 30th Annual International Solid Freeform Fabrication Symposium 44 (0) (2019) 1-14.

[6] D. K. Leigh, A comparison of polyamide 11 mechanical properties between laser sintering and traditional molding, 23rd Annual International Solid Freeform Fabrication Symposium - An Additive Manufacturing Conference, SFF 2012 (2012) $574-605$.

[7] T. Stichel, T. Frick, T. Laumer, F. Tenner, T. Hausotte, M. Merklein, M. Schmidt, A Round Robin study for Selective Laser Sintering of polyamide 12: Microstructural origin of the mechanical properties, Optics and Laser Technology 89 (October 2016) (2017) 31-40. doi:10.1016/j.optlastec.2016.09.042.

URL http://dx.doi.org/10.1016/j.optlastec.2016.09.042

[8] J. Kruth, G. Levy, R. Schindel, T. Craeghs, E. Yasa, Consolidation of Polymer Powders by Selective Laser Sintering, in: International Conference on Polymers and Moulds Innovations, 2008, pp. 15-30.

[9] J. P. Kruth, G. Levy, F. Klocke, T. H. C. Childs, Consolidation phenomena in laser and powder-bed based layered manufacturing, CIRP Annals - Manufacturing Technology 56 (2) (2007) 730-759. doi:10.1016/j.cirp.2007.10.004.

[10] Y. Shi, Z. Li, H. Sun, S. Huang, F. Zeng, Effect of the properties of the polymer materials on the quality of selective laser sintering parts (2004).

[11] H. Zarringhalam, N. Hopkinson, N. F. Kamperman, J. J. de Vlieger, Effects of processing on microstructure and properties of SLS Nylon 12, Materials Science and Engineering A 435-436 (2006) 172-180. doi:10.1016/j.msea.2006.07.084.

[12] M. Garcia-Leiner, M. T. Reitman, M. J. El-Hibri, R. K. Roeder, Structure-Property Relationships in Commercial PEEK Resins, Polymer Engineering and Science (2017) 955-964doi:10.1002/pen.24472.

[13] U. Ajoku, N. Hopkinson, M. Caine, Experimental measurement and finite element modelling of the compressive properties of laser sintered Nylon-12, Materials Science and Engineering A 428 (1-2) (2006) 211-216. doi:10.1016/j.msea.2006.05. 019.

[14] W. Zhu, C. Yan, Y. Shi, S. Wen, J. Liu, Y. Shi, Investigation into mechanical and microstructural properties of polypropylene manufactured by selective laser sintering in comparison with injection molding counterparts, Materials and Design 82 (2015) 37-45. doi:10.1016/j.matdes.2015.05.043. URL http://dx.doi.org/10.1016/j.matdes.2015.05.043 
[15] Y. Wang, J. D. Beard, K. E. Evans, O. Ghita, Unusual crystalline morphology of Poly Aryl Ether Ketones (PAEKs), RSC Adv. 6 (4) (2016) 3198-3209. doi:10.1039/C5RA17110E.

URL http://www.scopus.com/inward/record.url?eid=2-s2.0-84954170797\&partnerID=tZOtx3y1

[16] A. J. Lovinger, D. D. Davis, Electron-microscopic investigation of the morphology of a melt-crystallized polyaryletherketone, Journal of Applied Physics 58 (8) (1985) 2843-2853. doi:10.1063/1.335856.

[17] K. H. Gardner, B. S. Hsiao, R. R. Matheson Jr., B. A. Wood, Structure, Crystallization and Morphology of Poly ( aryl ether ketone ketone ), Polymer 33 (12) (1992) 1752-1758.

[18] D. J. Blundell, A. B. Newton, Variations in the crystal lattice of PEEK and related para-substituted aromatic polymers: 2. Effect of sequence and proportion of ether and ketone links, Polymer 32 (2) (1991) 308-313. doi:10.1016/0032-3861 (91) 90019-F.

[19] P. Avakian, K. H. Gardner, R. R. M. Jr., A comment on crystallization in PEKK and PEEK resins, Journal of Polymer Science Part C: Polymer Letters 28 (8) (1990) 243-246. doi:doi.org/10.1002/pol.1990.140280801.

[20] M. Garcia-Leiner, D. P. Dennies, A. Yardimci, High Performance Polymers in Additive Manufacturing Processes: Understanding Process, Structure and Property, Microscopy and Microanalysis 21 (S3) (2015) 127-128. doi:10.1017/ S1431927615001439.

URL http://www.journals. cambridge.org/abstract_S1431927615001439

[21] Arkema, Kepstan 6000 Series (2013).

URL https://www.arkema.com/export/shared/.content/media/downloads/products-documentations/incubator/ arkema-kepstan-6000-tds.pdf

[22] T. Choupin, B. Fayolle, G. Régnier, C. Paris, J. Cinquin, B. Brulé, Isothermal crystallization kinetic modeling of poly(etherketoneketone) (PEKK) copolymer, Polymer 111 (2017) 73-82. doi:10.1016/j.polymer.2017.01.033.

[23] L. Benedetti, B. Brulé, N. Decraemer, K. E. Evans, O. Ghita, Evaluation of particle coalescence and its implications in laser sintering, Powder Technology 342 (2019) 917-928. doi:10.1016/j.powtec.2018.10.053.

URL https://doi.org/10.1016/j.powtec.2018.10.053

[24] IBM, IBM SPSS software. Accessed in April, 2020.

URL https://www.ibm.com/uk-en/analytics/spss-statistics-software

[25] Mettler Toledo, Differential Scanning Calorimetry for all Requirements (2011).

[26] F. Paolucci, M. J. H. van Mook, L. E. Govaert, G. W. M. Peters, Influence of post-condensation on the crystallization kinetics of PA12: From virgin to reused powder, Polymer 175 (March) (2019) 161-170. doi:10.1016/j.polymer.2019. 05.009 .

URL https://doi.org/10.1016/j.polymer.2019.05.009

[27] X. Tardif, B. Pignon, N. Boyard, J. W. P. Schmelzer, V. Sobotka, D. Delaunay, C. Schick, Experimental study of crystallization of PolyEtherEtherKetone (PEEK) over a large temperature range using a nano-calorimeter, Polymer Testing 36 (2014) 10-19. doi:10.1016/j.polymertesting.2014.03.013.

URL http://dx.doi.org/10.1016/j.polymertesting.2014.03.013

[28] L. Benedetti, B. Brulé, N. Decreamer, K. Evans, O. Ghita, Shrinkage behaviour of semi-crystalline polymers in laser sintering: PEKK and PA12, Materials \& Design 181 (2019) 107906. doi:10.1016/j.matdes.2019.107906.

URL https://linkinghub.elsevier.com/retrieve/pii/S0264127519303442

[29] R. D. Goodridge, C. J. Tuck, R. J. Hague, Laser sintering of polyamides and other polymers, Progress in Materials Science 57 (2) (2012) 229-267. doi:10.1016/j.pmatsci.2011.04.001.

URL http://dx.doi.org/10.1016/j.pmatsci.2011.04.001

[30] S. Dupin, O. Lame, C. Barrès, J. Y. Charmeau, Microstructural origin of physical and mechanical properties of polyamide 12 processed by laser sintering, European Polymer Journal 48 (9) (2012) 1611-1621. doi:10.1016/j. eurpolymj.2012.06. 
007.

[31] S. Berretta, K. E. Evans, O. Ghita, Processability of PEEK, a new polymer for high temperature laser sintering (HT-LS), European Polymer Journal 68 (2015) 243-266. doi:10.1016/j.eurpolymj.2015.04.003.

URL http://dx.doi.org/10.1016/j.eurpolymj.2015.04.003

[32] S. Berretta, K. E. Evans, O. R. Ghita, Predicting processing parameters in high temperature laser sintering (HT-LS) from powder properties, Materials and Design 105 (2016) 301-314. doi:10.1016/j.matdes.2016.04.097.

URL http://dx.doi.org/10.1016/j.matdes.2016.04.097

[33] H. Motz, J. M. Schultz, The Solidification of PEEK. Part II: Kinetics, Journal of Thermoplastic Composite Materials 2 (4) (1989) 267-280. doi:10.1177/089270578900200402.

URL http://jtc.sagepub.com/content/2/4/267.abstract

[34] J. D. Hoffman, J. I. Lauritzen Jr., Crystallization of Bulk Polymers With Chain Folding : Theory of Growth of Lamellar Spherulites, Journal of Research of the National Bureau of Standards - A. Physics and Chemistry 65 (August) (1961) 1961. doi: 10.6028/jres.065A.035.

[35] O. R. Ghita, E. James, R. Trimble, K. E. Evans, Physico-chemical behaviour of Poly (Ether Ketone) (PEK) in High Temperature Laser Sintering (HT-LS), Journal of Materials Processing Technology 214 (4) (2014) 969-978. doi:10.1016/ j.jmatprotec.2013.11.007.

[36] EOS E-Manufacturing Solutions, EOS PEEK HP3, the high-grade performer (2008). URL https://webbuilder5.asiannet.com/ftp/2684/sheet_07-08_en_provisional.pdf

[37] I. H. Hillier, Modified Avrami Equation for the Bulk Crystallization Kinetics of Spherulitic Polymers, Journal of Polymer Science: Part A 3 (1965) 3067-3078.

URL http://onlinelibrary.wiley.com/doi/10.1002/pol.1965.100030902/epdf?r3_referer=wol\&tracking_ action=preview_click\&show_checkout=1\&purchase_referrer=onlinelibrary $\cdot$ wiley $\cdot$ com\&purchase_site_license= PUBLICATION_OUTSIDE_OF_LICENSE_PERIOD

[38] T. Choupin, Mechanical performances of PEKK thermoplastic linked to their processing parameters, Ph.D. thesis, ParisTech (2018).

[39] P. G. Kossakowski, Influence of initial porosity on strength properties of S235JR steel at low stress triaxiality, Archives of Civil Engineering 58 (3) (2012) 293-308. doi:10.2478/v.10169-012-0017-9.

[40] H. G. Van Melick, L. E. Govaert, H. E. Meijer, Prediction of brittle-to-ductile transitions in polystyrene, Polymer 44 (2) (2002) 457-465. doi:10.1016/S0032-3861(02)00770-X.

[41] P. properties database, BRITTLE-DUCTILE BEHAVIOR OF AMORPHOUS POLYMERS (2015). URL http://polymerdatabase.com/polymerphysics/Brittle-DuctileBehavior.html

[42] Additive Industries, Industrial solutions for metal additive manufacturing (2019). URL https://www.additiveindustries.com/

[43] EOS E-Manufacturing Solutions, Additive Manufacturing, Laser-Sintering and industrial 3D printing - Benefits and Functional Principle (2019).

URL https://www.eos.info/additive_manufacturing/for_technology_interested 